\title{
A Culturally-sensitive Approach to Elderly Care
}

\section{Gunn-Tove Minde}

Harstad University College, Norway

\begin{abstract}
This chapter takes a culturally sensitive approach to elderly care. The elderly are ethnic Norwegians, the Sami Indigenous people and the Kven minorities in the Arctic region in Norway. How can an older person rediscover his or her dignity when they arrive in nursing homes? Cultural values, beliefs and worldviews are anchored in "the living body." This means that the human's biological conditions are woven together with life experiences and interpretations thereof. The most important motivator in rediscovering the older person`s dignity in nursing homes lies in the interaction between the older person and service workers who have a culturally-sensitive approach. This means that the social and health providers see the older person as a complete person, not just his or her bodily and cognitively impairment. By using a person-sentred care in milieu therapy in the nursing homes, the students were preserving health and continuity in the lives of elderly patients.
\end{abstract}

Keywords: Arctic people; Indigenous culture; Culturally-sensitive approach; Case studies; Older people; Nursing home; Health; Continuity

\section{Introduction}

In this article the author will present three case studies from the nursing home which is done by social and health care students during their second year at their bachelor studies. As a part of their learning program, the students have 10 weeks practice during each year in the social and health sector. As a university teacher in sociology and cultural understanding the author of this article has the responsibility to give them a reflective practice to enable them to act cultural-sensitive in their milieu therapy among older people during their practice and in future working life. The growing elderly population in Western societies is a challenge for these countries, including Norway [1]. There is also an increase in dementia among older people in home care and in nursing homes [2]. Nearly 80 percent of elderly in nursing homes in Norway are suffering from Dementia [3]. When older people are moving to nursing homes, they lost their connection with their home and their cultural environment. Older people living in the Arctic region in Northern Scandinavia, have live in close connection with the nature, especially the Indigenous Sami people. With the word Arctic the author mean the ethnic Norwegian, the Indigenous Sami people and the Kven people, person of Finnish descent in Northern Norway. Several researchers mean that activity and participation are important in later life, reduce illnesses, and promote health and wellbeing. They mean that such activities have more effect than medication for example with depression [4-7]. In Norway there have been a lot of research done on health issues, but on elderly care there are just been few studies among older Sami and Kven people in Norway [8,9]. In recent time there has been done a qualitative study on older South Sami people and how they experiences being old and receiving home care [9]. People working in the health and social service sector usually stress that they do not make any distinction between Sami and non-Sami users. However, this is usually the problem. Sami users are made to feel invisible, which often risks obstructing them form verbalizing their unique health problems. By seeing the old Sami persons as an old ethnic Norwegian the nurses neglect the Sami cultural identity and worldview [9].

One of the challenges of conducting research on successful aging in nursing homes, is the lack of data or research on culture and aging in nursing homes. The Sami Indigenous population and the Kven minorities are in need of meeting personnel with knowledge about their history and culture and acknowledge that language barriers can be an obstacle in order to have a good interaction during treatment meetings $[10,11]$. Nymo/Minde find that there is a challenge being sick and living in a minority situation. Communications problems and stigma from the Colonization period is still there and can appear in different ways when illness occurs [8]. The Indigenous patient's home and environment is a health care system in itself. Being in the cultural landscape and coming home, is of great importance to recover. Over all the realities of the Indigenous and minority elders have been neglected when sorting out successful and unsuccessful agers in nursing homes. Studies from other regions and countries show that home, nature, cultural environment and outside spaces in old age are important for wellbeing and successful ageing in many different cultures [12] Cultural values and understandings of the world are anchored in "the living body". This means that the human's biological conditions are woven together with life experiences and interpretations of the experiences. Cultural understanding depends of what kind of concept you choose. The concept culture has a lot of meanings. In addition to symbolic elements such as values and norms, culture includes a wide range of physical human creations called artifacts as cultural landscape, housing, food, clothes (Sami:gakti, Japanese:kimono), language, music etc. Culture is also lived experiences in outside spaces and social environment. Cultural landscape in this text is the interaction between nature, human beings, animals and birds and the tracks they have made in the landscape. The Indigenous patient's home and environment is a health care system in itself. Being in the cultural landscape and coming home, is of great importance. It gives them feeling of belonging and connection [8]. Further research needs to be conducted.

In this essay I will describe the outcome of social and health care students' experiences with person-centered in nursing homes. In order to promote health and wellbeing in nursing homes, the health personnel needs to take into account also the social, cultural and spiritual needs of the older person. Health and wellbeing in nursing home depend of sense of coherence [13]. This study hope to address this gap in the literature and serves as an example of why we need to explore healthy living in nursing home in general, but specific for older Indigenous people and older ethnic minorities. The research question is

*Corresponding author: Gunn-Tove Minde, Dep of Health and social sevices, Havnegt 5 Harstad, Troms 460 Norway, Tel: +4795790510; E-mail: gunn.minde@hih.no

Received August 30, 2015; Accepted September 20, 2015; Published September 23, 2015

Citation: Minde G (2015) A Culturally-sensitive Approach to Elderly Care. J Gerontol Geriatr Res 4: 249. doi:10.4172/2167-7182.1000249

Copyright: (c) 2015 Minde G. This is an open-access article distributed under the terms of the Creative Commons Attribution License, which permits unrestricted use, distribution, and reproduction in any medium, provided the original author and source are credited. 
what happen between the students and the old person during 10 weeks in nursing homes.

\section{The Context}

Our empiric impact area is colonization areas in the Arctic region in Norway. By Sami colonization areas we mean areas that are geographically close to areas that are seen as Norwegian and where the Norwegian language has competed with the Sami language. Areas like these are among others the rural Sami districts in the Arctic region in Norway. Even if the majority of the Samis in the rural Sami districts have lost their Sami language, they have a strong Sami identity. Many Sami living in the Colonized area to-day define themselves as ethnic Norwegians [14]. The Norwegian state's statutory colonization program, activated in the mid 1880's, lasting for 100 years, contributed to that Sami people became stigmatized, and many hid their ethnic identity due to the shame of being part of an ethnic minority. The acculturation process for people living in northern Norway has been a long process [15]. The health and social care for minorities has been an integrated part of the Norwegian health- and social care program. They are taken care of as ordinary ethnic Norwegians. There are no space for Sami language, values, norms and mentality in the nursing homes in Norway to-day [16]. In a recent study from the South Sami area, the equal findings are observed. People working in the health and social service sector usually stress that they do not make any distinction between Sami and non-Sami users. However, this is usually the problem. Sami users are made to feel invisible, which often risks obstructing them form verbalizing their unique health problems. By seeing the old Sami persons as an old ethnic Norwegian the nurses neglect the Sami cultural identity and worldview [9].

\section{Person-centred Care}

Person-centred care is a thinking and doing things that sees the people using health and social services as equal partners in planning, developing and monitoring care to make sure it meets their needs. This means putting people and their families at the centre of decisions and seeing them as experts, working alongside professionals to get the best outcome. Person-centred care is not just about giving people whatever they want or providing information. It is about considering people's desires, values, family situations, social circumstances and lifestyles; seeing the person as an individual, and working together to develop appropriate solutions. Being compassionate, thinking about things from the person's point of view and being respectful are all important. This might be shown through sharing decisions with patients and helping people manage their health, but person-centred care is not just about activities. It is as much about the way professionals and patients think about care and their relationships as the actual services available [17]. In the past, people were expected to fit in with the routines and practices that health and social services felt were most appropriate [18]. But in order to be person-centred, services need to change to be more flexible to meet people's needs in a manner that is best for them. This involves working with people and their families to find the best way to provide their care. This partnership working can occur on a one-toone basis, where individual people take part in decisions about their health and care, or on a collective group basis whereby the public or patient groups are involved in decisions about the design and delivery of services. The underlying philosophy is the same: it is about doing things with people, rather than 'to' them. There is no one definition of person-centred care. People might also use terms such as patientcentred, family-centred, user-centred, individualised or personalized.

\section{Method: A Case Study Approach}

I have been working in the academic fields almost 20 years with Artic topics and cultural understanding in different academic institutions. The last seven years as a teacher at Harstad University College, Norway. The pedagogic work for me as a tutor is to teach the students in how to implement cultural understanding in their future work as professional in health and social service sector. When working with older Indigenous people and older ethnic minorities in nursing and health care, cultural competence is cornerstone [9]. The culturally competent health worker needs to understand his/her views of the world and those of the client, while avoiding stereotyping and misapplication of scientific knowledge.

The production of data to this article are based on material collected by the students during their second year of their bachelor studies. During a period of two years the author has been a tutor for 10 case studies in elderly care where the author undertake a secondtime analysis. Three of the case studies are presented in this article. At the end of the ten weeks period the students choose one older person they take special care of. This person is usually an older sick man or a woman to whom the student has developed a special relationship. The second-time analysis is a kind of comprehensive study of the students essays and interpretation of literature that relate to this particular topic.

\section{Why to use a case study approach}

A case study was chosen because there have been few studies of successful aging in nursing home that have consider what role culture plays in this construct. Second because the author want to analyze the process between the students and the older person over a period, and the factors that influenced the relationship between them. According to Yin [19] a case study design should be considered when you want to cover contextual conditions because we believe they are relevant to the phenomenon under study. On the other side, using this approach is also valuable for health science research to develop theory, evaluate programs and develop interventions because of its flexibility and rigor [19].

\section{Ethical considerations}

The student were asked to share their papers with me for publication which they gave their informed consent to. The older people have given their informed consent to the students and guaranteed confidentially. No individual characteristics were to be disclosed in reporting the results. A telephone to the Norwegian Social Science Data Service give me the permission to use the paper in research work.

\section{The case studies}

In the following sections I will present Ruth, Jørgen and Ida. They are all born in Northern Norway. Ruth and Jørgen is ethnic Norwegian and speak Norwegian language, Ida is a Sami-speaking women.

\section{Ruth}

Ruth is a widow of 75 years. She has 4 children and 11 grandchildren. She has worked the whole life. She is the head of the family. Active in volunteering No she is in a nursing home after a serious stroke. She is paralyzed in one leg, depressed because of her new situation and complaining all day long, shouting about going home. During the 10 weeks the student takes special care of Ruth. One day the student decides to organize a visit to her homeplace. She colaborates with Ruth `s youngest daughter. The visit to Ruth `s homeplace change Ruth `s attitude. The effect is that Ruth stops complaining and shouting. She is in a remarkable better mood after visiting her homeplace. From now on, she is doing progress in her health situation. 


\section{Jørgen}

Jørgen is 80 -years old and lives in a small town in NorthernNorway. He has been working in a bank the whole life. He is married and has two children and five grandchildren. After the stroke, he moved to a nursing home. It is hard for him. He feels lonely among many women both patients and staff. He became aggressive both to his wife and to his female residents. The student takes special care of Jørgen. She organizes a reminisens-group together with another man. The student gets in contact with a bank, and asks for old coins and money which is the starting point for the conversation between the three people. The effect of this milieu therapy is that Jørgen is in better mood and no more aggressive to his wife or his women residents.

\section{Ida}

Ida is unmarried, 80 years old and a Sami-speaking woman. She doesn 't want the other residents to know about her Sami identity. She lives in a nursing home in a multicultural municipality with both ethnic Norwegian, Sami and Finnish heritage people. She is suffering from dementia, and has started to forget her narrow-minded upbringing. The students take special care of Ida. One day the student starts talking Sami language to Ida. Ida is offended. Why does the student speak Sami language too her? She denied first being a Sami. She does not want to have anything to do with the student after this. The student and Ida have no personal contact during 14 days. One day Ida invites the student into her room, asks her to close the door and tells her about her that she is a Sami-speaking person. She doesn 't want anyone in the nursing home to know about it.

The result after 10 weeks milieu therapy is that Ida is proud being a Sami woman. She is not afraid to show her Sami identity- an old Sami woman among the other residents in the nursing home. She is happy and satisfied.

\section{Results}

I have presented three different situations from three multicultural municipalities in Northern Norway. According to the students, finding the home place, social space and the language have come forward as meaningful factors. The older patient's home, cultural landscape, employment history and mother tongue is important for the elderly's subjective health and quality of life. Being in the cultural landscape and coming home is of great importance. It gives them feeling of belonging and connection. The students show a through understanding of human beings i.e human beings as something more than just a body and a diagnosis in a nursing home-they are also cultural and spiritual beings with specific needs and lived experiences.

\section{Analysis and Discussion}

The informants' stories speak for themselves. There are also differences in what they emphasize during our conversations. Their illness and background reflect individual experiences. They have some features in common. In their narratives, the informants place themselves in a specific context. Identity comes forward. Even if they have collective understandings of situations, they express themselves differently depending on the situation. With serious illness, the human being is forces into a new situation. Many move into nursing homes. Some take a long time to understand the situation and depression occurs. It seems as if they need to clarify to themselves how their body is actually doing and come to understand the resources available to meet the situation.

One of the students used the reminiscence method and organized a reminiscence group. The student adopted symbols from the material culture as money from the old person's working life. She found local resource, e.g. she looked for old money from the time Jørgen worked in a bank. She went to the local library and borrowed books to read about the town as it was 30 years ago. The student borrowed artifacts from the museum. Retirement is a transition for many people, especially for men [1]. Some feel that retirement is a kind of freedom to do what they want, especially the working class people. For some, the profession has been more than a necessity to earn a living. Jørgen's profession has been a career that has given him pride and identity. That's why the transition from workplace to retirement has led to a loss of self-esteem for many older men [1]. For Jørgen, the transition led to withdrawal from the social life. Through the group process, Jørgen rediscovers an integrated identity due to his function. He was in good mood, and he felt better.

The story of Ruth shows a person with challenging behavior. The student managed to cooperate and communicate with Ruth in order to understand the old woman's need. Ruth was beginning to trust the young student. The student choose to take Ruth back home-to a house she had to leave when she suffered a stroke. The purpose was to reduce her homesickness. The student contacted Ruth`s daughter who helped the student organize a home visit and introduce the idea to Ruth. Ruth was delighted. A somatic illness leaves much to process in a short period of time. It is therefore important for the nursing home to be a place where the old people can process their life-transitions and illnesses. Many old people struggle to feel a sense of home at nursing homes [20]. Home is often theorized as multidimensional and defined as a dwelling place or a lived space of interaction between people, places, things $[8,21]$ and animals. It is more than a place to live. The environment and the outside space hold a central place in the lives of older people [12]. Home provides a context for many valued roles and activities for promoting health [22]. Many health providers don't understand the losses the elderly are suffering when they must leave home. The student understood Ruth's situation and her need to visit home. After the visit, Ruth understood that it was impossible for her to stay in the house in her new condition. After the visit to her home, she changed. She was more satisfied with her current life.

In relation to Ida, the student used her cultural competence in order to connect with her. She used her cultural awareness to understand the whole picture of Ida i.e seeing that Ida has a Sami identity. Ida reacted when the student spoke the Sami language to her. This surprised the students, even though she is from a municipality where the Sami people is in the majority. Here almost $90 \%$ speak the Sami language. The student didn't understand the situation among the Coastal Sami people, who have been exposed to assimilation, racism and ethnic discrimination. Several of the old Sami people experienced ethnic bullying in their childhood and youth and are still ashamed of being a Sami, even the situation today has improved. However, over the course of several weeks, Ida's attitude changed. She acknowledged that her identity is nothing to be ashamed of. She told the student that she is a Sami-speaking woman.

In order to understand Ida's situation, it is important to understand the diversity among the Sami people in Northern Norway. Ida is at a nursing home in the colonized area where most of the Sami people speak the Norwegian language. They still maintain a strong Sami identity [23]. A minority population is relative i.e. a minority can only exist in relation to a majority and visa versa [9]. Hearing the Sami language awoke something in Ida. Life suddenly became meaningful. She found 
a "soul" friend she can communicate with in the Sami language in the nursing home. Ida didn't have to hide her Sami identity anymore; she gained awareness of who she is and opened up for more contact with the student and, later on, the other residents.

Basically the students in this study were highly motivated to gain cultural competence and avoid stereotyping and misunderstanding. They grew up in the northernmost county and have developed a thorough cultural competence. The Sami student had also experienced the on-going subtle colonization some of the older patients have experienced. The student's listening to their stories and their subtle narratives about their minority situation led to noticeable recognition and validation on the part of the patient. In the encounters with the elderly the students own worldviews, beliefs and values are discovered and employed. They obtained cultural information and then applied that knowledge. The cultural awareness allows the students to see the entire picture and improve the quality of care and the health outcomes. Through the reminiscence group, the home visit, and using the Sami language, the students promoted the health and wellbeing of the elderly clients. By the same token, the elderly clients gained more awareness about themselves. They were happier and friendlier toward the other clients, family and staff.

The older Artic people of Northern Norway has been a colonized people for several years [15]. Additionally there is an on-going subtle colonization that the Sami people are still exposed to in nursing homes [9]. That is why it is important to implement cultural-competence techniques in order to gain more equality among the older clients and the staff. These findings are transferable to other indigenous and ethnic minorities among the growing older population in Western countries, especially among groups with unprecedented cultural diversity whom health and social staff face daily

\section{Methodological Considerations}

The article focuses on the experiences of older people in northern Norwegian nursing homes, especially focusing on the care they received in the nursing homes. The first author's students carried out the initial analysis; however, the second author has reflected on and continuously and critically worked with the assessments. This interpretation represents what has been found to be the most useful way of understanding of this phenomenon. The strength of the analyses is due to ten weeks of student fieldwork in a nursing home with one of the authors acting as the students' tutor. The weakness is that the data is based on a) novise researchers work and b) a secondary analysis of how older people experienced life in nursing homes. The stories are unique, and the author interpretation is one of many possible interpretations of each situation. Therefore, the intention of this article is to illustrate a culturally-sensitive approach in the encounter between the older person and the student and the successful aging process.

\section{Conclusions}

The growing elderly population in Western societies is a challenge for these countries, including Norway. A culturally-sensitive approach to elderly care helps to promote independence and strengthens the health strategies among the elderly. Experiences from earlier interactions with public health initiatives are embodied in life experiences. The students understood his/her own view of the world and those of the clients. During their field work the students' changed their perspective during the ten-week practice to a more culturally-sensitive approach. This opened their eyes and ears, and they understood and recognized the underlying values, beliefs and identities of the elderly. This leant dignity to everyone, including the Indigenous Sami patient. The most important motivator in rediscovering the dignity of the elderly in nursing homes seemed to lie in the hands of the social and health staff with a culturally-sensitive approach. Maybe this is the most convenient perspective in elderly care in a time with increasing elderly population in Western societies. Culturally-sensitive care is also a necessary approach in municipalities with elderly indigenous people and older ethnic minorities.

\section{Conflict of Interest and Funding}

The author has not received any funding or benefits from industry or elsewhere to conduct the study.

\section{References}

1. Daatland HO, Solem PE (2011) Aging and Society. An introduction to socialgerontology. Bergen: Fagbokforlaget.

2. Engedal K, Haugen PK (2009) Dementia Facts and challenges.. Tønsberg: Aldring og helse.

3. Telenius EW, Engedal K, Bergland A (2015) Effect of a high-intensity exercise program on physical function and mental health in nursing home residents with dementia: an assessor blinded randomized controlled trial. PLoS One 10: e0126102.

4. Dahan-Oliel, Gelinas, Mazer (2008) Social participation in the elderly: What does the litterature tell? Psysical and Rehabilitation Medicine 20: 159-176.

5. Silverstein M, Parker MG (2002) Leirsure activities and quality of life among the old in Sweden. Research on Aging 24: 528-547.

6. Stav WB, Hallenen T, Lane J, Arbesman M (2012) Systematic review of occupational engagement and health outcomes among community-dwelling older adults. Am J Occup Ther 66: 301-310.

7. Thorsen K, Clausen SE (2008) Disability, lowliness and depression: What does loneliness means for persons suffering from disability who experiences depression. Tidsskrift for Norsk Psykologforening 45: 19-27.

8. Nymo R, Minde GT (2014) Open the medical room - how Indigenous patient's cultural knowledge appears in the meeting with the health care providers during the rehabilitation process. Samhandlingsreformen under lupen. Kassah, Thingvoll, Kassah (red). Bergen: Fagbokforlaget.

9. Ness TM (2013) Experiences of being old and receiving home nursing care Older South Sami narrations of their experiences - An interview study. Open Journal of Nursing 3: 1-7.

10. Norwegian Directorate of Health (2009) Report on development centres for nursing home services for the Sami population.

11. Simonsen RA (2014) What does equality means for the Sami population? Masterpiece in social anthropology. UIT-The Arctic University.

12. [No authors listed] (2014) Creating Culturally Appropriate Outside Spaces and Experiences for People with Dementia Marshall Mary and Gilliard Jane Creating Culturally Appropriate Outside Spaces and Experiences for People with Dementia 168pp £19.99 Jessica Kingsley 97818490551471849055149 [Formula: see text]. Nurs Older People 26: 10.

13. Antonovsky A (2012) Unraveling the mystery of health. The Salutogenetic model. Oslo: Gyldendal akademisk.

14. Nergård Jl (2007). The living experience. Bergen: Fagbokforlaget

15. Edvardsen E (1997) The Arctic Man. Oslo: Pax forlag.

16. Minde GT (2004) Critical Perspective on institutions. Help in context. Tronvoll Moe, Henriksen (red). Porsanger: Idut forlag

17. Rokstad AMM (2014) See who I am! Person-sentered care with dementia Oslo: Universitetsforlaget.

18. Kitwood T (1999) Dementia reconsidered. Fredrikshavn: Dafolo Forlag.

19. Yin RK (2003) Case study research: Design and methods. Thousand Oaks, Ca: Sage Person-centred care and why it is important. 
20. Heggestad AKT (2014) To be taken seriously as a human being. A qualitative study on dignity in dementia care, Oslo: Universitetet i Oslo.

21. Mallett S (2004) Understanding Home: A critical review of the litterature. The Sociological Review 52: 62-89.
22. Minde GT (2010) To live their Soul. Health and vitality among women in Northern Troms. Bodø: Licentia forlag.

23. Hansen KL, Melhus M, Høgmo A, Lund E (2008) Ethnic discrimination and bullying in the Sami and non-Sami populations in Norway: the SAMINOR study. Int J Circumpolar Health 67: 97-113. 